\title{
Ecrivains de la Préhistoire, textes réunis par Andre Benhaim et Michel Lantelme
}

\section{Elisa Bricco}

\section{(2) OpenEdition \\ 1 Journals}

\section{Edizione digitale}

URL: http://journals.openedition.org/studifrancesi/35212

DOI: 10.4000/studifrancesi.35212

ISSN: 2421-5856

Editore

Rosenberg \& Sellier

\section{Edizione cartacea}

Data di pubblicazione: 1 novembre 2005

Paginazione: 452

ISSN: 0039-2944

\section{Notizia bibliografica digitale}

Elisa Bricco, «Ecrivains de la Préhistoire, textes réunis par Andre Benhaim et Michel Lantelme», Studi Francesi [Online], 146 (XLIX | II) | 2005, online dal 30 novembre 2015, consultato il 19 avril 2021. URL: http://journals.openedition.org/studifrancesi/35212; DOI: https://doi.org/10.4000/studifrancesi. 35212

Questo documento è stato generato automaticamente il 19 avril 2021.

\section{(c)}

Studi Francesi è distribuita con Licenza Creative Commons Attribuzione - Non commerciale - Non opere derivate 4.0 Internazionale. 


\title{
Ecrivains de la Préhistoire, textes réunis par Andre Benhaim et Michel Lantelme
}

\author{
Elisa Bricco
}

\section{NOTIZIA}

Ecrivains de la Préhistoire, textes réunis par ANDRE BeNHAIM et MICHEL LANTELME, P. U. du Mirail «Essais littérature - Cribles», 2004.

1 Il volume sulla letteratura della preistoria si apre con una presentazione alquanto seducente che permette al lettore di penetrare la materia trattata e di apprezzarla appieno (André BERNHAïM, Par la grande porte, pp.7-10). La preistoria, il tempo più distante da noi, ha esercitato un fascino molto forte sugli scrittori del XIX secolo, e ancora oggi continua a «intrigare» i letterati. Dopo un excursus sulla storia del romanzo di argomento preistorico (Claudine COHEN, pp.11-31), e alcuni approfondimenti su romanzi famosi come La Guerre $d u$ feu, sul rapporto di Proust al tempo, di Malraux alle origini e di Bataille alla storia dell'arte attraverso Lascaux, si passa ad alcuni interessanti saggi sulla prosa contemporanea. Pascal Quignard e il suo rapporto con Lascaux e tutto quello che la preistoria porta in sé in quanto possibilità di ritorno al tempo delle origini, dell'origine e all'inizio del tempo, in relazione naturalmente alle possibilità espressive della scrittura, è al centro dello studio di Stéphanie BOULARD, Ecrire après Lascaux: Pascal Quignard romancier, pp.115-127. In Duras filme, la confusion des temps, Stéphane PATRICE studia un cortometraggio, Les Mains négatives, la cui idea primaria ha origine in alcune pitture preistoriche che la scrittrice aveva visto e che erano rimaste impresse nella sua memoria. Le mani in negativo delle caverne sono accompagnate da quelle moderne che appaiono nelle immagini durasiane, creando così un cuntinuum temporale e stimolando la riflessione sul destino umano (pp.129-142). Di tutt'altro genere la preistoria evocata da Jean Rouaud (Michel 
LANTELME, La Grotte Rouaud, pp. 143- 158) nei suoi romanzi, in particolare in Des hommes illustres in cui la casa famigliare è evocata quasi fosse una grotta preistorica, e il padre è descritto come uomo preistorico; inoltre le notazioni concernenti le epoche lontane sono frequenti nei romanzi e altri testi dello scrittore. Il romanzo Préhistoire di Eric Chevillard è preso in esame molto dettagliatamente da Bruno BLANCKEMAN ( De la Préhistoire à l'après-histoire, pp.159-176), che dopo un breve ma esaustivo e lucido panorama della fascinazione del romanzo contemporaneo per la preistoria, si addentra nelle pieghe di un testo complesso e quasi «preistorico». La tesi che sviluppa l'autore è che il romanzo attuale sia ormai al di là da ogni possibile tentativo di storicizzazione, al di là da ogni possibile «questionnement». Chiude il volume un interessante intervista a Eric Chevillard, Questions de préhistoire (propos recueillis par André BENHEÏM, pp. 177-190). 